\title{
Observation of three distinct ion populations at the Kelvin-Helmholtz-unstable magnetopause
}

\author{
M. G. G. T. Taylor ${ }^{1}$ and B. Lavraud ${ }^{2, *}$ \\ ${ }^{1}$ ESTEC/European Space Agency, Noordwijk, The Netherlands \\ ${ }^{2}$ Space Science and Applications, Los Alamos National Laboratory, Los Alamos, NM, USA \\ *now at: Centre d'Etude Spatiale des Rayonnements, CNRS, Toulouse, France
}

Received: 19 December 2007 - Revised: 1 April 2008 - Accepted: 16 April 2008 - Published: 11 June 2008

\begin{abstract}
We report Double Star spacecraft observations of the dusk-flank magnetopause and its boundary layer under predominantly northward interplanetary magnetic field (IMF). Under such conditions the flank low-latitude boundary layers (LLBL) of the magnetosphere are known to broaden. The primary candidate processes associated with the transport of solar wind plasma into the LLBL are: (1) local diffusive plasma transport associated with the KelvinHelmholtz instability (KHI), (2) local plasma penetration owing to magnetic reconnection in the vicinity of the KHIdriven vortices, and (3) via a pre-existing boundary layer formed through double high-latitude reconnection on the dayside. Previous studies have shown that a cold population of solar wind origin is typically mixed with a hot population of magnetospheric origin in the LLBL. The present observations show the coexistence of three distinct ion populations in the dusk LLBL, during an interval when the magnetopause is unstable to the KHI: (1) a typical hot magnetospheric population, (2) a cold population that shows parallel temperature anisotropy, and (3) a distinct third cold population that shows perpendicular temperature anisotropy. Although no unambiguous conclusion may be drawn from this single event, we discuss the possible mechanisms at work and the origin of each population by envisaging three likely sources: hot magnetospheric plasma sheet, cold magnetosheath of solar wind origin, and cold plasma of ionospheric origin.
\end{abstract}

Keywords. Magnetospheric physics (Magnetotail boundary layers; Plasma sheet; Solar wind-magnetosphere interactions)

\section{Introduction}

The magnetopause boundary layers have been the subject of intensive study over the years (e.g. Rosenbauer et al., 1975; Eastman et al., 1976; Mitchell et al., 1987). Their formation has been attributed to several plasma entry mechanisms, of which magnetic reconnection (e.g. Song and Russell, 1992; Paschmann et al., 1993; Fuselier et al., 1997) and diffusive entry, including the Kelvin-Helmholtz instability (e.g. Terasawa et al., 1997; Johnson and Cheng, 1997, 2001; Fujimoto et al., 1998; Hasegawa et al., 2004), are the most favored (see also Scholer and Treumann, 1997, and Sibeck et al., 1999, for reviews).

The mechanism at work primarily depends on the IMF $B_{Z}$. Under southward IMF, magnetic reconnection allows plasma to flow through the dayside magnetopause, probably in a continuous (although possibly sporadic) and efficient fashion (Dungey, 1961; Cowley, 1982). Under northward IMF, however, it is unclear which of the above-mentioned mechanisms is most efficient. High-latitude reconnection is most likely to occur at the magnetopause tailward of the cusps (e.g. Kessel et al., 1996; Safrankova et al., 1998; Lavraud et al., 2002). Song and Russell (1992) proposed that the formation of the low-latitude boundary layer (LLBL) may stem from reconnection occurring in both hemispheres for the same magnetic field lines, thus capturing solar wind plasma on newly closed field lines. This scenario was given support through satellite observations (Le et al., 1996; Onsager et al., 2001; Lavraud et al., 2005, 2006) and MHD simulations (e.g. Ogino et al., 1994; Fedder and Lyon, 1995; Raeder et al., 1997; Song et al., 1999; Li et al., 2005).

Diffusive processes have been suggested to occur at the magnetopause (e.g. Terasawa et al., 1997; Lee et al., 1994; Johnson and Cheng, 1997, 2001; Wing et al., 2006), but their efficiency has often been questioned (e.g. Scholer and Treumann, 1997; Bauer et al., 2001). The Kelvin-Helmholtz instability is not a plasma entry mechanism per se, but its

Correspondence to: M. G. G. T. Taylor

(mtaylor@rssd.esa.int)

Published by Copernicus Publications on behalf of the European Geosciences Union. 
occurrence is believed to be important for plasma transport at the flank magnetopause, in particular under northward IMF as it may allow local plasma penetration by favoring both magnetic reconnection (Otto and Fairfield, 2000; Nykyri and Otto, 2001) and diffusive processes (e.g. Matsumoto and Hoshino, 2006; Smets et al., 2007).

Some studies have suggested that double high-latitude reconnection is sufficient to form the LLBL and cold-dense plasma sheet (CDPS: Fujimoto et al., 1998) under northward IMF (Øieroset et al., 2005; Li et al., 2005). However, Hasegawa et al. (2004) noted that several observational facts argue against double high-latitude reconnection as a sufficient mechanism: (1) the thickness of the cold-dense boundary layers increases with distance away from the nose, as shown by Mitchell et al. (1987), indicating that plasma continuously enters along the flanks; (2) the occurrence of stagnant or even weakly sunward flow in the cold-dense boundary layers appears inconsistent with tailward transport of boundary layers formed on the dayside; (3) the stronger dependence of the flank cold-dense plasma occurrence frequency on IMF orientation, as compared to that in the subsolar region, is indicative of different entry processes; and (4) the continued high density of the boundary layer plasma well down on the flanks, at distances where flux tubes filled at the dayside would need to have expanded substantially, is not consistent with the expected adiabatic density decrease.

Finally, recent studies have shown a dawn-dusk asymmetry of the ion energy spectrum of the plasma sheet and LLBL under northward IMF conditions (Fujimoto et al., 1998; asegawa et al., 2003, 2004; Wing et al., 2005). This asymmetry is characterized by the predominance of a twocomponent ion energy distribution on the dusk flank, consisting of a cold-dense component of solar wind origin and a hotter magnetospheric population. On the dawn flank, these two components are less easily discerned and the population has been considered as a single, broader mixed distribution. The preferential dawn-dusk magnetic drift of energetic ions in the tail has been suggested to explain the preferential appearance of the hot magnetospheric population at dusk. Nishino et al. (2007a) investigated the characteristics of the (single) cold ion component at the dusk LLBL and found that it has stronger parallel anisotropy at larger distances downtail. Here we will show that, at least for the present event, the cold-dense ion population observed in the LLBL at dusk may in fact consist of two distinct populations, in addition to the hot population of magnetospheric origin.

Whether the Kelvin-Helmhotz instability substantially drives transport of plasma into the magnetosphere is still under debate. Understanding the signatures associated with plasma entry at the flanks is key to determining the efficiency of the various proposed entry mechanisms under northward IMF.

\section{Summary of previous study by Taylor et al. (2008)}

In the present paper we show Double Star 1 observations of a magnetopause crossing on 5 December 2004. A multispacecraft study of this event was presented previously by Taylor et al. (2008). They discussed the formation of the LLBL and CDPS during this event in terms of the differences and similarities observed at several spacecraft located at various positions in the magnetosphere and along the dusk magnetopause.

Taylor et al. (2008) examined the nature of the quasiperiodic fluctuations at the flank magnetopause (also shown in the current paper in Fig. 1). By using an MHD simulation, seeded with in-situ measurements, it was shown that the local magnetopause conditions were conducive to the development of the KHI. Further analysis of general properties of the plasma and field fluctuations led to the conclusion that the boundary waves were rolled up into vortex structures. This conclusion was drawn from the occurrence of large tailward flows (larger than that of the magnetosheath itself) characterized by relatively low densities (typical of the magnetosphere). Such feature may only be expected for fully rolledup vortex geometries, as explained in details by Hasegawa et al. (2006), and has been proposed as an indication of local plasma transport through the boundary (Hasegawa et al., $2004,2006)$. In the present paper, we focus only on the ion distribution functions observed by Double Star-1 within the boundary layers.

\section{Observations}

We use data from the Double Star 1 spacecraft, in particular from the Hot Ion Analyzer (HIA; Rème et al., 2005), which measures full three-dimensional (3-D) ion (without mass discrimination) distribution functions in the energy range 5$32 \mathrm{keV} / \mathrm{q}$ (32 energy steps) every spin (4s), with an angular resolution of $11.25^{\circ} \times 22.5^{\circ}$. The moments shown here come from straight integration of the distribution functions onboard the spacecraft. The full 3-D distributions transmitted on ground and from which the distributions in this paper are draw are accumulated over 2 spins $(8 \mathrm{~s})$ and have an angular resolution of $22.5^{\circ} \times 22.5^{\circ}$. We also use spin resolution magnetic field measurements from the Flux Gate Magnetometer (FGM; Carr et al., 2005). Solar wind conditions are taken from high resolution OMNI data (King and Papitashvili, 2005). We show ACE magnetic field (Smith et al., 1998) and plasma (McComas et al., 1998) measurements. The OMNI data are time-shifted to the bow shock nose.

Figure 1 shows an overview of the Double Star and ACE data for the time period 17:40-21:20 UT on 5 December 2004, with Double Star location given at the bottom. During the time period shown, Double Star is located at the dusk flank magnetopause close to the terminator, and having just passed apogee, is inbound to the magnetosphere. At the 


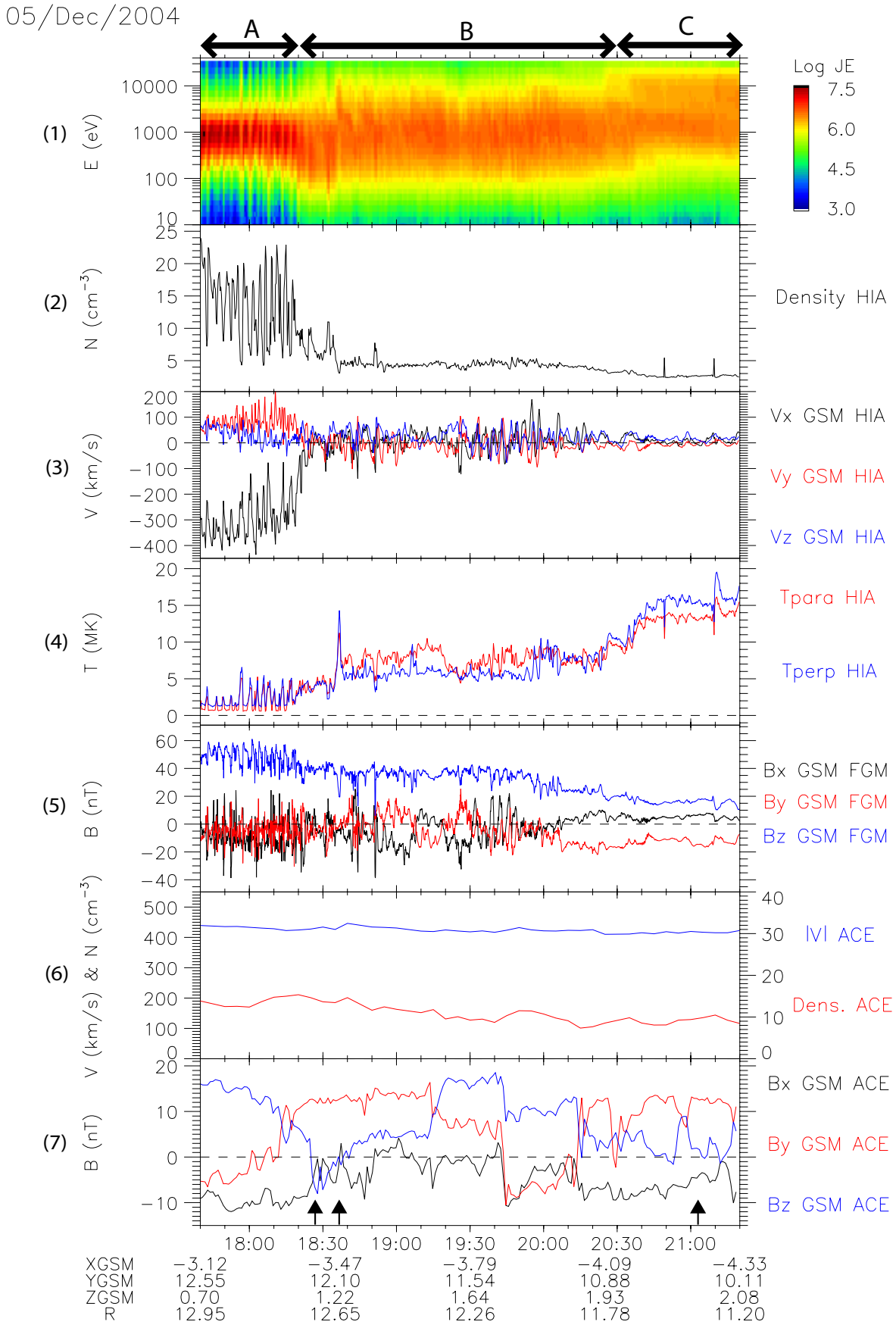

Fig. 1. Double Star 1 and ACE data for the time period 17:40-21:20 UT on 5 December 2004. The panels show the HIA ion (1) omnidirectional energy-time spectrogram, (2) density, (3) velocity components in GSM coordinates, and (4) parallel and perpendicular temperature. The following panels show (5) FGM magnetic field components in GSM, (6) ACE solar wind velocity magnitude and density, and (7) ACE magnetic field components in GSM. Double Star 1 location is indicated below the time axis. Three arrows show the time at which the ion distributions of Fig. 2 were sampled.

beginning of the period, denoted interval (A) in Fig. 1, the ion and magnetic field observations are characterized by quasiperiodic fluctuations. The spacecraft alternatively samples pristine cold, flowing magnetosheath plasma and somewhat hotter, more tenuous plasma typical of flank boundary layers. The period of the fluctuations is $\sim 2-3 \mathrm{~min}$, in agreement with previous observations of Kelvin-Helmholtz-driven fluctuations (e.g. Fairfield et al., 2000) and the data is consistent 

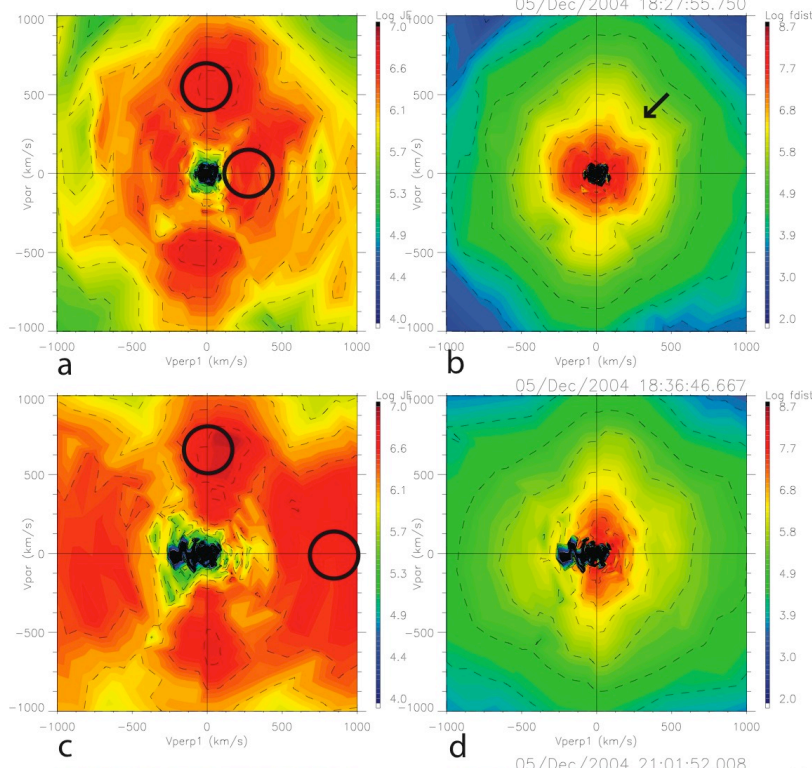

b
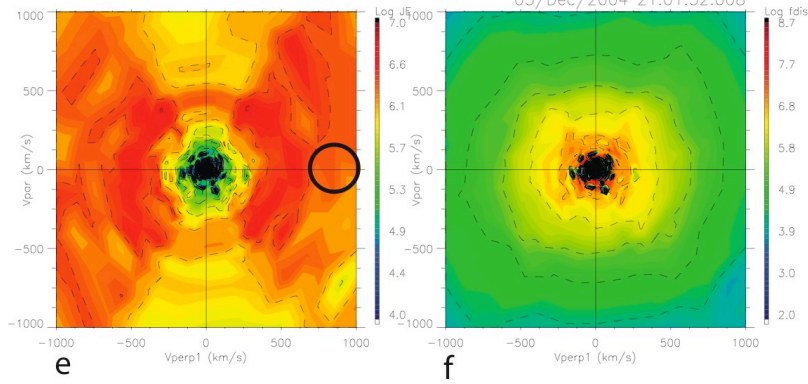

Fig. 2. Double Star 1 ion distribution functions in the form of cuts in the $\left(V_{/ /}, V_{\perp}\right)$ plane (relative to the magnetic field). The times at which these distributions were sampled are shown with arrows in Fig. 1. Note that these plots are zooms which show the distributions only for ion speeds up to $1000 \mathrm{~km} / \mathrm{s}$. The right-hand column shows ion distribution functions in phase space density units (PSD) $\left(\mathrm{s}^{3} \mathrm{~km}^{-6}\right)$, while the left-hand column shows the same distributions in energy flux units (JE) $\left(\mathrm{keV} \mathrm{cm}^{-2} \mathrm{~s}^{-1} \mathrm{sr}^{-1} \mathrm{keV}^{-1}\right)$. The circles in (a), (c) and (e), and the arrow in (b) are used to emphasize parts of the distribution discussed in the text.

with the occurrence of rolled-up vortices, as shown previously in Taylor et al. (2008). The following interval (B) is characterized by a hotter, more tenuous population typical of flank LLBL. As shown in the next paragraph, several populations coexist in this boundary layer region. During the last interval (C), the predominant ion population observed is a hot population (panel 1), although weak fluxes are also observed at lower energies. This hotter and more tenuous population is the plasma sheet and is typically observed inward of the LLBL.

In Fig. 2 we show three representative ion distribution functions from intervals (B) and (C) in Fig. 1. Ion distribution functions from the flowing magnetosheath are not shown. These are trivially very distinct from those shown in
Fig. 2. All distribution functions show cuts in the $\left(V_{/ /}, V_{\perp}\right)$ plane (relative to the magnetic field). Note that these plots show zooms on the core of the distributions and that the velocity scale has been reduced to emphasize the distributions. The actual highest velocities (i.e. energies) measured by HIA are more than twice higher than the limit of $1000 \mathrm{~km} / \mathrm{s}$ shown in these plots. The right-hand column shows ion distribution functions in phase space density units (PSD) $\left(\mathrm{s}^{3} \mathrm{~km}^{-6}\right)$ and the left-hand column shows the same distributions in energy flux units (JE) $\left(\mathrm{keV} \mathrm{cm}^{-2} \mathrm{~s}^{-1} \mathrm{sr}^{-1} \mathrm{keV}^{-1}\right)$. While energy flux is not typically used to display such distribution functions, it is used here to better highlight the presence of several embedded populations at the lowest energies.

The key observation here is the ion distribution function from 18:27:55.750 UT shown in Fig. 2a and b and which shows the presence of two distinct populations at low energies (one part of each is indicated by circles in Fig. 2a). The first cold population is observed as a primarily bi-directional population, elongated along the magnetic field direction. It is thus characterized by a parallel temperature anisotropy $\left(T_{/ /}>T_{\perp}\right)$. The second cold population is primarily observed in the perpendicular direction; it is characterized by a perpendicular temperature anisotropy. That those two populations are indeed distinct is observable in the fact that the phase space densities (Fig. 2b) and energy fluxes (Fig. 2a) at about $45^{\circ}$ from both the field-aligned and perpendicular directions show dips in the absolute PSD and JE values. We indicate one such dip with an arrow in Fig. 2b. Because the dips observed in the parallel and anti-parallel directions are measured by different anodes, and because no dips are observed in adjacent regions, they are not the result of an instrumental problem.

That the two populations observed in Fig. $2 \mathrm{a}$ and $\mathrm{b}$ are distinct is further confirmed by considering Fig. $2 \mathrm{c}$ and d, from 18:36:46.667 UT. At this particular time within the boundary layer, a temporal or spatial change occurs, which likely led the spacecraft to sample an innermost region of the boundary layer so that the hotter magnetospheric ion population appears, primarily in the perpendicular direction, as indicated by the right-most circle in Fig. 2c. We note the continued existence of the cold bi-directional ion population with parallel temperature anisotropy (again indicated by a black circle). Finally, a characteristic ion distribution function of the hot plasma sheet from the end of interval (C) (Fig. 1) is shown in Fig. 2e and f. It shows a hot ion population with perpendicular temperature anisotropy, as expected for such a region.

The interesting feature of Fig. $2 \mathrm{c}$ and $\mathrm{d}$ is that the cold ion population showing parallel temperature anisotropy is clearly present. It has the same characteristics as in Fig. 2a and b and is here mixed with the hotter plasma sheet ion population. However, the second, cold population primarily observed in the perpendicular direction in Fig. 2a and b is not present at this time. This also suggests that the two cold populations observed in Fig. 2a and b are distinct and possibly the result of different entry mechanisms and/or origins. 
We note that the absolute values of the parallel and perpendicular temperatures (panel 4 of Fig. 1) are somewhat variable during interval (B). However, ion distribution functions showing the presence of two cold populations, such as in Fig. 2a and b, are observed throughout interval (B), apart from the short interval when the distributions of Fig. 2c and $\mathrm{d}$ are sampled. No time-aliasing effect is therefore expected.

The IMF is strongly northward during interval (A) in Fig. 1, but it rotates towards a more horizontal direction (dominant $B_{Y}>0$ ) during the first part of interval (B). This fact could lead us to believe that processes other than the Kelvin-Helmholtz instability (e.g. magnetic reconnection) may be locally active at such times, owing to this new IMF orientation (or that KHI activity is not limited to strongly northward IMF periods). This would complicate the interpretation of the ion distribution functions given in Sect. 4 below. However, the distribution function of Fig. 2a and $b$ is sampled very close to the magnetopause, at a time when the local magnetosheath field was strongly northward just a few minutes before (and had been for a substantial time). Therefore, we believe that this distribution function is characteristic of the Kelvin-Helmholtz-unstable magnetopause at the dusk flank, at least for this event.

Finally, we note that no counterpart to these three ion populations have been discerned in the electron distribution functions. The higher thermal velocity of electrons renders such a distinction much harder than for ions.

\section{Discussion}

As suggested by Hasegawa et al. $(2004,2006)$, such a rolledup magnetopause may imply local plasma transport. The Kelvin-Helmholtz instability can be envisaged as a mechanism of solar wind entry mediated by diffusion, as a result of secondary instabilities, wave-particle interaction, etc. (e.g. Wilber and Winglee; 1995; Jonhson and Cheng, 2001; Sibeck et al., 1999; Matsumoto and Hoshino, 2006; Smets et al., 2007). As proposed by several authors (Otto and Fairfield, 2000; Nykyri et al., 2006; Nishino et al., 2007b, c) the development of KHI-driven vortices can induce magnetic reconnection in the vicinity of rolled-up structure and hence solar wind entry. Under northward IMF, numerous studies have provided evidence for the occurrence of double highlatitude reconnection (see introduction). That a pre-existing boundary layer formed via this mechanism was present prior to the occurrence of the KHI along the flanks is also envisaged in the following. Together with the solar wind plasma entry mechanisms involved, we now discuss of the ion populations observed during this event.
4.1 Origin of the hot population with perpendicular temperature anisotropy

The hot ion population with perpendicular temperature anisotropy (observed in Fig. 2c, d, e, and f), and that is primarily observed during interval (C) in Fig. 1, obviously comes from the magnetotail plasma sheet. It is believed to be preferentially observed in the dusk LLBL as a result of magnetic drifts (Fujimoto et al., 1998; Hasegawa et al., 2003).

4.2 Origin of the cold population with perpendicular temperature anisotropy

Ion populations with perpendicular temperature anisotropy have been observed in the dawn LLBL (e.g. Hasegawa et al., 2003), and particle simulations have shown that diffusive transport via the KHI may lead to ion perpendicular anisotropy in the boundary layers (Wilber and Winglee, 1995). Wing et al. (2006) also proposed that diffusion by Kinetic Alfvén Waves (KAW) can explain such anisotropy at dawn, on the basis of the work by Johnson and Cheng (1997, 2001). As discussed by Sibeck et al. (1999), the development of the KHI may further generate KAW-induced diffusion. Therefore, the cold ion population showing a perpendicular anisotropy may be the result of diffusive transport owing the KHI.

Another possibility is that this population comes from a pre-existing boundary layer formed by double high-latitude reconnection on the dayside. As shown by Nishino et al. (2007a), the LLBL on the dayside show less parallel temperature anisotropy, i.e., are more isotropic, than in the nightside. The LLBL on the dayside are not generated by the KHI owing to the lack of velocity shear there. The double highlatitude reconnection origin is thus also plausible.

Cold ionospheric plasma tends to be field-aligned when observed in the tail. This is due to the conservation of the first adiabatic invariant along magnetic field lines (with decreasing field magnitude). An ionospheric source for the cold ion population with perpendicular anisotropy is thus less likely.

\subsection{Origin of the cold population with parallel temperature anisotropy}

Diffusion within Kelvin-Helmholtz vortices leading to the entry of solar wind plasma with parallel temperature anisotropy has never been suggested to the author's knowledge, apart from the very specific case of Smets et al. (2007) for an anti-parallel field orientation. However, reconnection induced in the KHI-driven vortices, as suggested in both modeling and observational studies (e.g. Otto and Fairfield, 2000; Nykyri et al., 2006; Nishino et al., 2007b, c) may lead to flows along the magnetic field near the KHI vortices. In Nykyri et al. (2006), three cases of parallel ion beams were observed which were interpreted as reconnection signatures due to the KHI. These dawn flank observations were made 
under strong tangential IMF conditions. In the current case, although on the dusk flank, draping of the IMF during the period of dominant tangential $\left(+\mathrm{Y}_{\mathrm{GSM}}\right)$ component could produce similar conditions. It is thus possible that the cold ion population with parallel temperature anisotropy is the result of reconnection having occurred both north and south of the spacecraft, i.e. in order to explain the bi-directionality, as suggested by Nishino et al. (2007c).

Another plausible explanation is that this population comes from double high-latitude reconnection. This possibility is supported by the observation of Fig. $2 \mathrm{c}$ and d, where only the cold population with parallel temperature anisotropy is observed (together with the hot plasma sheet). Such distribution functions (Fig. 2c and d) are typically seen during the early part of interval (C) in Fig. 1, i.e. at the transition between the LLBL and the plasma sheet (Fig. 2e and f). Thus, the cold ion population with parallel temperature anisotropy seems to be observed on the more inner parts of the LLBL. This may be consistent with it having been built prior to the ongoing KHI locally at the boundary. On the other hand, there is no clear explanation as to why a population formed via double high-latitude reconnection should show such anisotropy, or why it should retain it during transport from the dayside. This explanation is also incompatible with the observation of Nishino et al. (2007a, b) that the cold population is more isotropic on the dayside than in the tail LLBL.

Finally, a plausible explanation is that the cold ion population with parallel temperature anisotropy comes from an ionospheric source (outflows), which as explained above should exhibit such anisotropy. However, we also note that ionospheric outflow is found to be weaker under periods of Northward IMF (Øieroset et al., 1999). This source may not be confirmed here since the HIA instrument on Double Star does not allow for species determination.

\section{Concluding remarks}

We have presented ion distribution functions in the lowlatitude boundary layer (LLBL) at the Kelvin-Helmholtzunstable dusk flank magnetopause. These undoubtedly show the presence of two cold ion populations, one showing a parallel temperature anisotropy and the second showing a perpendicular one, together with the typical hot plasma sheet population. This is to be contrasted with previous studies of the LLBL that generally were considering a single cold ion population (see introduction).

That such ion distribution functions have not been reported previously may stem from: (1) the lack of detectors with sufficient energy-angular resolution, (2) the location of the observation; proximity to the terminator may correspond to the beginning of plasma entry mediated by the Kelvin-Helmholtz instability while more scattering may be expected as time elapses along the flanks downtail, and (3) the possible exis- tence of an ionospheric population which may not be always present at the flanks.

No definitive conclusion may be reached for the origin of the two cold ion populations, and for the solar wind plasma entry mechansims that could lead to such properties. In future work we will look for more events, focusing on Cluster dataset with composition measurements. Also, modeling efforts directed towards determining the anisotropies of the solar wind-originated ions in the LLBL would be most relevant.

Acknowledgements. We thank the Cluster and Double Star instrument leaders for their help: CIS/HIA (H. Rème and I. Dandouras) and FGM (C. Carr). We would like to thank M. W. Dunlop and the International Space Science Institute in Bern, Switzerland, in particular B. Fasler, S. Saliba and V. Manno, for setting up and for supporting the "Comparative Cluster-Double Star Measurements of the Dayside Magnetosphere" team from which this work was developed. We would also like to thank M. F. Thomsen for useful discussions. We acknowledge the use of ACE MFI and SWEPAM instruments data and the CDAWeb for providing those. Work at Los Alamos was conducted under the auspices of the US Department of Energy, with support from NASA Guest Investigator, Living With a Star, Cluster/PEACE and Cluster/ RAPID MO\&A grant NNG04E.

Topical Editor I. A. Daglis thanks M. N. Nishino and another anonymous referee for their help in evaluating this paper.

\section{References}

Bauer, T. M., Treumann, R. A., and Baumjohann, W.: Investigation of the outer and inner low-latitude boundary layers, Ann. Geophys., 19, 1065-1088, 2001

Carr, C., Brown, P., Zhang, T. L., Gloag, J., Horbury, T., Lucek, E., Magnes, W., O’Brien, H., Oddy, T., Auster, U., Austin, P., Aydogar, O., Balogh, A., Baumjohann, W., Beek, T., Eichelberger, H., Fornacon, K.-H., Georgescu, E., Glassmeier, K.-H., Ludlam, M., Nakamura, R., and Richter, I.: The Double Star magnetic field investigation: instrument design, performance and highlights of the first year's observations, Ann. Geophys., 23, 27132732, 2005,

http://www.ann-geophys.net/23/2713/2005/.

Cowley, S. W. H.: The causes of convection in the Earth's magnetosphere: a review of developments during the IMS, Rev. Geophys. Space Phys., 20(3), 531-565, 1982.

Dungey, J. W.: Interplanetary magnetic field and the auroral zones, Phys. Rev. Lett., 6(2), 47-48, 1961.

Eastman, T. E., Hones Jr., E. W., Bame, S. J., and Asbridge, J. R.: The magnetospheric boundary layer-site of plasma, momentum and energy transfer from the magnetosheath into the magnetosphere, Geophys. Res. Lett., 3, 685-688, 1976.

Fairfield, D. H., Otto, A., Mukai, T., Kokubun, S., Lepping, R. P., Steinberg, J. T., Lazarus, A. J., and Yamamoto, T.: Geotail observations of the Kelvin-Helmholtz instability at the equatorial magnetotail boundary for parallel northward fields, J. Geophys. Res., 105(A9), 21 159-21 173, 2000.

Fedder, J. A. and Lyon, J. G.: The Earth's magnetosphere is $165 R_{E}$ long: self-consistent currents, convection, magnetospheric struc- 
ture, and processes for northward interplanetary magnetic field, J. Geophys. Res., 100(A3), 3623-3635, 1995.

Fujimoto, M., Terasawa, T., Mukai, T., Saito, Y., Yamamoto, T., and Kokubun, S.: Plasma entry from the flanks of the near-Earth magnetotail: Geotail observations, J. Geophys. Res., 103, 43914408, 1998.

Fuselier, S. A., Anderson, B. J., and Onsager, T. G.: Electron and ion signatures of field line topology at the low-shear magnetopause, J. Geophys. Res., 102(A3), 4847-4863, 1997.

Hasegawa, H., Fujimoto, M., Maezawa, K., Saito, Y., and Mukai, T.: Geotail observations of the dayside outer boundary region: Interplanetary magnetic field control and dawn-dusk asymmetry, J. Geophys. Res., 108(A4), 1163, doi:1029/2002JA009667, 2003.

Hasegawa, H., Fujimoto, M., Phan, T. D., Rème, H., Balogh, A., Dunlop, M. W., Hashimoto, C., and TanDokoro, R.: Rolledup Kelvin-Helmholtz vortices and associated solar wind entry at Earth's magnetopause, Nature, 430, 755-758, 2004.

Hasegawa, H., Fujimoto, M., Takagi, K., Saito, Y., Mukai, T., and Rème, H.: Single-Spacecraft detection of rolled-up KelvinHelmholtz vortices at the flank magnetopause, J. Geophys. Res., 111, A09203, doi:10.1029/2006JA011728, 2006.

Johnson, J. R. and Cheng, C. Z.: Kinetic Alfvén waves and plasma transport at the magnetopause, Geophys. Res. Lett., 24(11), 1423-1426, 1997.

Johnson, J. R. and Cheng, C. Z.: Stochastic ion heating at the magnetopause due to kinetic Alfvén waves, Geophys. Res. Lett., 28(23), 4421-4424, 2001.

King, J. H. and Papitashvili, N. E.: Solar wind spatial scales in and comparisons of hourly Wind and ACE plasma and magnetic field data, J. Geophys. Res., 110(A2), A02209, doi:10.1029/2004JA010804, 2005.

Kessel, R. L., Chen, S.-H., Green, J. L., Fung, S. F., Boardsen, S. A., Tan, L. C., Eastman, T. E., Craven, J. D., and Frank, L. A.: Evidence of high-latitude reconnection during northward IMF: Hawkeye observations, Geophys. Res. Lett., 23(5), 583586, 1996.

Lavraud, B., Dunlop, M. W., Phan, T. D., Rème, H., Bosqued, J.M., Dandouras, I., Sauvaud, J.-A., Lundin, R., Taylor, M. G. G. T., Cargill, P. J., Mazelle, C., Escoubet, C. P., Carlson, C. W., McFadden, J. P., Parks, G. K., Moebius, E., Kistler, L. M., Bavassano-Cattaneo, M.-B., Korth, A., Klecker, B., and Balogh, A.: Cluster observations of the exterior cusp and its surrounding boundaries under northward IMF, Geophys. Res. Lett., 29(20), 56-60, doi:10.1029/2002GL015464, 2002.

Lavraud, B., Thomsen, M. F., Taylor, M. G. G. T., et al.: Characteristics of the magnetosheath electron boundary layer under northward IMF: Implications for high-latitude reconnection, J. Geophys. Res., 110, A06209, doi:10.1029/2004JA010808, 2005.

Lavraud, B., Thomsen, M. F., Taylor, M. G. G. T., Wang, Y. L., Phan, T. D., Schwartz, S. J., Elphic, R. C., Fazakerley, A. N. F., Rème, H., and Balogh, A.: Characteristics of the magnetosheath electron boundary layer under northward interplanetary magnetic field: Implications for high-latitude reconnection, J. Geophys. Res., 110(A6), A06209, doi:10.1029/2004JA010808, 2005.

Lavraud, B., Thomsen, M. F., Lefebvre, B., Schwartz, S. J., Seki, K., Phan, T. D., Wang, Y. L., Fazakerley, A., Rème, H., and Balogh, A.: Evidence for newly closed magnetosheath field lines at the dayside magnetopause under northward IMF, J. Geophys.
Res., 111(A5), A05211, doi:10.1029/2005JA011266, 2006.

Le, G., Russell, C. T., Gosling, J. T., and Thomsen, M. F.: ISEE observations of low-latitude boundary layer for northward interplanetary magnetic field: Implications for cusp reconnection, J. Geophys. Res., 101(A12), 27 239-27 249, 1996.

Lee, L. C., Johnson, J. R., and Ma, Z. W.: Kinetic Alfvén waves as a source of plasma transport at the dayside magnetopause, $\mathrm{J}$. Geophys. Res., 99(A9), 17 405-17411, 1994.

Li, W. H., Raeder, J., Dorelli, J., Øieroset, M., and Phan, T. D.: Plasma sheet formation during long period of northward IMF, Geophys. Res. Lett., 32(12), L12S08, doi:10.1029/2004GL021524, 2005.

Matsumoto, Y. and Hoshino, M.: Turbulent mixing and transport of collsionless plasmas across a stratified velocity shear layer, J. Geophys. Res., 111, A05213, doi:10.1029/2004JA010988, 2006.

McComas, D. J., McComas, Bame, S. J., Barker, P., Feldman, W. C., Phillips, J. L., Riley, P., and Griffee, J. W.: Solar Wind Electron Proton Monitor (SWEPAM) for the Advanced Composition Explorer, Space Sci. Rev., 86, 563-612, 1998.

Mitchell, D. G., Kutchko, F., Williams, D. J., Eastman, T. E., Frank, L. A., and Russell, C. T.: An extended study of the low-latitude boundary layer on the dawn and dusk flank of the magnetosphere, J. Geophys. Res., 92(A7), 7394-7404, 1987.

Nishino, M. N., Fujimoto, M., Terasawa, T., Ueno, G., Maezawa, K., Mukai, T., and Saito, Y.: Geotail observations of temperature anisotropy of the two-component protons in the dusk plasma sheet, Ann. Geophys., 25, 769-777, 2007a, http://www.ann-geophys.net/25/769/2007/.

Nishino, M. N., Fujimoto, M., Terasawa, T., Ueno, G., Maezawa, K., Mukai, T., and Saito, Y.: Temperature anisotropies of electrons and two-component protons in the dusk plasma sheet, Ann. Geophys., 25, 1417-1432, 2007b, http://www.ann-geophys.net/25/1417/2007/.

Nishino, M. N., Fujimoto, M., Terasawa, T., Ueno, G., Mukai, T., and Saito, Y.: Origin of temperature anisotropies in the cold plasma sheet: Geotail observations around the Kelvin-Helmholtz votices, Ann. Geophys., 25, 2069-2086, 2007c, http://www.ann-geophys.net/25/2069/2007/.

Nykyri, K. and Otto, A.: Plasma Transport at the Magnetospheric Boundary due to Reconnection in Kelvin-Helmholtz Vortices, Geophys. Res. Lett., 28(18), 3565-3568, 2001.

Nykyri, K., Otto, A., Lavraud, B., Mouikis, C., Kistler, K. M., Balogh, A., and Rème, H.: Cluster observations of reconnection due to the Kelvin-Helmholtz instability at the dawnside magnetospheric flank, Ann. Geophys., 24, 2619-2643, 2006, http://www.ann-geophys.net/24/2619/2006/.

Ogino, T., Walker, R. J., and Ashour-Abdalla, A.: A global magnetohydrodynamic simulation of the response of the magnetosphere to a northward turning of the interplanetary magnetic field, J. Geophys. Res., 99(A6), 11 027-11 042, 1994.

Øieroset, M., Yamauchi, M., Liszka, L., and Hultqvist, B.: Energetic ion outflow from the dayside ionosphere: Categorization, classification, and statistical study, J. Geophys. Res., 104(A11), 24 915-24 927, 1999.

Øieroset, M., Raeder, J., Phan, T. D., Wing, S., McFadden, J. P., Li, W., Fujimoto,M., Rème, H., and Balogh, A.: Global cooling and densification of the plasma sheet during an extended period of purely northward IMF on October 22-24, 2003, Geophys. Res. Lett., 32(12), L12S07, doi:10.1029/2004GL021523, 2005. 
Onsager, T. G., Scudder, J. D., Lockwood, M., and Russell, C. T.: Reconnection at the high latitude magnetopause during northward interplanetary magnetic field conditions, J. Geophys. Res., 106(A11), 25 467-25 488, 2001.

Otto, A. and Fairfield, D. H.: Kelvin-Helmholtz instability at the magnetotail boundary: MHD simulation and comparison with Geotail observations, J. Geophys. Res., 105(A9), 21 175-21 190, 2000.

Paschmann, G., Baumjohann, W., Sckopke, N., Phan, T. D., and Luehr, H.: Structure of the dayside magnetopause for low magnetic shear, J. Geophys. Res., 98(A8), 13 409-13 422, 1993.

Raeder, J., Berchem, J., Ashour-Abdalla, M., Frank, L. A., Paterson, W. R., Ackerson, K. L., Kokubun, S., Yamamoto, T., and Slavin, J. A.: Boundary layer formation in the magnetotail: Geotail observations and comparisons with a global MHD simulation, Geophys. Res. Lett., 24(8), 951-954, 1997.

Rème, H., Dandouras, I., Aoustin, C., Bosqued, J. M., Sauvaud, J. A., Vallat, C., Escoubet, P., Cao, J. B., Shi, J., BavassanoCattaneo, M. B., Parks, G. K., Carlson, C. W., Pu, Z., Klecker, B., Moebius, E., Kistler, L., Korth, A., Lundin, R., et al.: The HIA instrument on board the Tan Ce 1 Double Star near-equatorial spacecraft and its first results, Ann. Geophys., 23(8), 2757-2774, 2005.

Rosenbauer, H., Gruenwaldt, H., Montgomery, M. D., Paschmann, G., and Sckopke, N.: HEOS-2 plasma observations in the distant polar magnetosphere: the plasma mantle, J. Geophys. Res., 80(19), 2723-2737, 1975.

Safrankova, J., Nemecek, Z., Sibeck, D. G., Prech, L., Merka, J., and Santolik, O.: Two-point observation of high-latitude reconnection, Geophys. Res. Lett., 25, 4301-4304, 1998.

Scholer, M. and Treumann, R. A.: The low-latitude boundary layer at the flank magnetopause, Space Sci. Rev., 80(1-2), 341-367, 1997.

Sibeck, D. G., Paschmann, G., Treumann, R. A., Fuselier, S. A., Lennartsson, W., Lockwood, M., Lundin, R., Ogilvie, K. W., Onsager, T. G., Phan, T.-D., Roth, M., Scholer, M., Sckopke, N., Stasiewicz, K., and Yamauchi, M.: Plasma Transfer Processes at the Magnetopause, Space Sci. Rev., 88, 207-283, 1999.

Smets, R., Belmont, G., Delcourt, D., and Rezeau, L.: Diffusion at the Earth magnetopause: enhancement by Kelvin-Helmholtz instability, Ann. Geophys., 25, 271-282, 2007, http://www.ann-geophys.net/25/271/2007/.
Smith, C. W., L'Heureux, J., Ness, N. F., Acuña, M. H., Burlaga, L. F., and Scheifele, J.: The ACE Magnetic Fields Experiment, Space Sci. Rev., 86, 613-632, 1998.

Song, P. and Russell, C. T.: Model of the formation of the lowlatitude boundary layer for strongly northward interplanetary magnetic field, J. Geophys. Res., 97(A2), 1411-1420, 1992.

Song, P., De Zeeuw, D. L., Gombosi, T. I., Groth, C. P. T., and Powell, K. G.: A numerical study of the solar wind-magnetosphere interaction for northward interplanetary magnetic field, J. Geophys. Res., 104(A12), 28 361-28 378, 1999.

Terasawa, T., Fujimoto, M., Mukai, T., Shinohara, I., Saito, Y., Yamamoto, T., Machida, S., Kokubun, S., Lazarus, A. J., Steinberg, J. T., and Lepping, R. P.: Solar Wind control of density and temperature in the near-Earth plasma sheet: WIND/GEOTAIL collaboration, Geophys. Res. Lett., 24, 935-938, 1997.

Taylor, M. G. G. T., Lavraud, B., Escoubet, C. P., Milan, S. E., Dunlop, M. W., Nykyri, K., Davies, J. A., Friedel, R. H. W., Frey, H., Bogdanova, Y. V., Åsnes, A., Laakso, H., Trávnícek, P., Masson, A., Opgenoorth, H., Vallat, C., Fazakerley, A. N., Lahiff, A. D., Owen, C. J., Pitout, F., Pu, Z., Shen, C., Zong, Q.-G., Rème, H., Scudder, J., and Zhang, T.-L.: The plasma sheet and boundary layers under northward IMF: a multi-point and multiinstrument perspective, Adv. Space Res., 41(10), 1619-1629, doi:10.1016/j.asr.2007.10.013, 2008.

Wilber, M. and Winglee, R. M.: Dawn-dusk asymmetries in the low-latitude boundary layer arising from the Kelvin-Helmholtz instability: A particle simulation, J. Geophys. Res., 100(A2), doi:10.1029/94JA02488, issn: 0148-0227, 1995.

Wing, S., Johnson, J. R., Newell, P. T., and Meng, C.-I.: DawnDusk asymmetries, ion spectra, and sources in the northward interplanetary magnetic field plasma sheet, J. Geophys. Res., 110, A08205, doi:10.1029/2005JA011086, 2005.

Wing, S., Johnson, J. R., and Fujimoto, M.: Timescale for the formation of the cold-dense plasma sheet: A case study, Geophys. Res. Lett., 33(23), L23106, doi:10.1029/2006GL027110, 2006. 